\title{
Superando a Dicotomia Sujeito $x$ Coletividade nas Organizações
}

\section{Overcoming Subject Dicotomy vs. Collectivity in Organizations}

\author{
Alex Fernandes Magalhães \\ Universidade Federal de Minas Gerais (UFMG) \\ email:alexfm@face.ufmg.br
}

\section{Luiz Alex Silva Saraiva}

Universidade Federal de Minas Gerais (UFMG)

email: saraiva@face.ufmg.br

\section{RESUMO}

Nesse ensaio, o objetivo é refletir sobre a complexidade inerente aos espaços sócio-organizacionais buscando superar a dicotomia sujeito $\times$ coletividade para abarcar os fenômenos de modo ampliado para evitar análises organizacionais reducionistas. Para tanto, elencam-se autores clássicos nas Ciências Sociais para um diálogo sobre a dinâmica sócio-organizacional articulando os sujeitos e suas práticas nas organizações e efeitos das inter-relações entre agentes que, por sua vez, cristalizam-se em dimensão institucional e servem, contraditoriamente, às produções subjetivas em meio aos espaços de socialização. Consideramos crítica a perspectiva aqui adotada por se voltar ao caráter sócio-histórico do objeto de análise, assim como por considerar contradições elementares na sua expressão e processualidade cotidianas. As principais contribuições se situam em torno da complexidade como marca das condições de produção social e subjetivas, orientando futuros trabalhos a não simplificá-las, considerando a variabilidade conceitual acerca do que se toma por organização social e suas interpretações.

Palavras-Chave: Organizações sociais; Sujeito; Dialética; Estudos organizacionais.
In this essay, the objective is to reflect on the complexity inherent to socio-organizational spaces, seeking to overcome the subject $\times$ collectivity dichotomy to encompass phenomena in a broader way to avoid reductionist organizational analysis. For this, classical authors in the Social Sciences are listed for a dialogue about socio-organizational dynamics articulating subjects and their practices organizations and effects to interrelationships between agents that, in turn, crystallize in an institutional dimension and serve contradictorily to the subjective productions in the midst of socialization spaces. We adopt a critical perspective for addressing socio-historical character to the object of analysis, as well as for considering elementary contradictions in its everyday expression and processuality. Main contributions are around complexity as a mark of the conditions of social and subjective production, guiding future works not to simplify them, considering the conceptual variability about what is taken by social organization and its interpretations.

Key-words: Social organizations; Subject; Dialectic; Organizational studies. 


\section{INTRODUCTION}

As concepções acerca dos espaços organizacionais são variáveis em função da diversidade teórica encontrada no âmbito das Ciências Humanas e Sociais. Nota-se muitas vezes uma tendência dicotômica quanto à articulação entre o sujeito e as organizações sociais, como se fosse possível compreender quaisquer dos elementos independentemente do outro. Embora as diversos teorias tenham trazido importantes possibilidades de descrição e explicação da sociedade a partir de seus variados recortes de estudo e pesquisa, não se superaram necessariamente os problemas próprios da dicotomia em questão. Dessa forma, muitas vezes parece natural aos profissionais nas organizações pensar que os sujeitos sociais são formados de modo determinado a partir de influências dos contextos que os circundam, com seus valores, normas, regras e demais elementos simbólicos essenciais a esse processo. Numa outra perspectiva, entretanto, os sujeitos é que são responsáveis pelos problemas sociais, que decorrem da maneira como naturalmente expressam, por meio de seus comportamentos, uma atitude egocentrada, marcada por individualismo, pouco se engendrando na construção de estratégias que se voltem para o bem comum.

Para Bastos et al. (2004), essa tensão e dicotomia de análise organizacional é reflexo da própria complexidade e multidimensionalidade das problematizações inerentes aos Estudos Organizacionais. Assim, esclarecem que as organizações podem ser tomadas tanto como processo - quando o indivíduo é elemento central para sua constituição - como por entidade, quando assumem um caráter maior que a reunião de indivíduos, conforme o quadro 1.

Essas visões se apresentam simplistas e reducionistas. E, quando tomadas isoladamente, acabam por ocultar tanto o papel das organizações na forma como os sujeitos se constituem quanto dos sujeitos sociais na produção dos próprios espaços organizacionais em que se situam. Reafirma-se aqui, no tocante à análise dos espaços organizacionais, que o olhar que direciona esse trabalho se baseia numa perspectiva dialética e voltada à complexidade: os sujeitos sociais são, ao mesmo tempo, produtores e produtos dos seus contextos coletivos, de maneira que a relação entre sujeitos sociais $\times$ espaços organizacionais não pode ser analisada senão pelas condições em que se produzem mutuamente junto às práticas cotidianas.

A dicotomia a que aqui se refere entre sujeito e sociedade tem justificativa política e ideológica no âmbito acadêmico. A história da Sociologia, por exemplo, explicita que os interesses quanto à consolidação de uma ciência voltada para os aspectos da vida em coletividade estavam centrados numa postura funcionalista e em prol da manutenção do status quo capitalismo, já que se acreditava - principalmente pelo ideário de Claude Saint-Simon (1760-1825) e Auguste Comte (1798-1857) - que o industrialismo e as transformações advindas com a modernidade trariam ordem e progresso à humanidade, desde que se abrisse mão de problemas de ordem metafísica em favor do utilitarismo, do pragmatismo e da objetividade, tal como se desenvolviam as ciências naturais.

Essa redução da realidade social ao empírico, embora tenha proporcionado à humanidade uma série de avanços com o desenvolvimento das diver-

Quadro 1 Dicotomia das análises das organizações

\begin{tabular}{|c|c|}
\hline $\begin{array}{l}\text { Processo } \\
\text { Indivíduo }\end{array}$ & $\begin{array}{c}\text { Entidade } \\
\text { Organização }\end{array}$ \\
\hline $\begin{array}{l}\text { As organizações são fluidas e resultam de processos de interação } \\
\text { Indivíduos são os únicos agentes causais. Deles dependem os } \\
\text { fenômenos organizacionais. } \\
\text { Indivíduos com poder definem características mais permanentes } \\
\text { das organizações: estrutura, normas, rotina. } \\
\text { Indivíduos com poder exercem influência ao modelar decisões } \\
\text { estratégicas. } \\
\text { Ações ditas organizacionais podem ser ações individuais. }\end{array}$ & $\begin{array}{l}\text { Há uma estrutura social prévia ao ingresso da pessoa (normas, } \\
\text { valores e expectativas). } \\
\text { Organizações tem o poder de moldar o comportamento ou ações } \\
\text { individuais. } \\
\text { Subsistem no tempo, independente das pessoas. } \\
\text { As organizações agem, têm políticas, fazem declarações. } \\
\text { As organizações aprendem e possuem culturas. } \\
\text { As organizações se relacionam com outras organizações e com } \\
\text { seu ambiente. }\end{array}$ \\
\hline
\end{tabular}

Fonte: Adaptado de Bastos et al. (2004). 
sas escolas e teorias clássicas nas Ciências Sociais, também é a responsável pela perda da complexidade relacionada ao sujeito e aos processos organizacionais. Tem-se como justificativa e entendimento aos reducionismos na história das ciências que também a própria história da humanidade e os acontecimentos que nela se inscrevem é que impulsionam a forma como se desenvolve o conhecimento e os modelos ou paradigmas que servem de base aos pesquisadores e comunidade acadêmica. Perceber, então, que a complexidade dos fenômenos atuais exige um novo direcionamento para proposições também complexas e abrangentes, é também uma exigência que se justifica histórica e socialmente. Neste ensaio, propõe-se uma concepção ampliada acerca das organizações sociais, como se estruturam, se processam e como atuam, concomitantemente, na configuração das subjetividades daqueles que nela se inserem, algo necessário para evitar os reducionismos nos Estudos organizacionais.

\section{UMA INCURSÃO NAS CONCEPÇÕES CLÁSSICAS ACERCA DO SOCIAL E SUA ORGANIZAÇÃO}

No que se refere ao desenvolvimento da Sociologia e as possibilidades de explicação e entendimento dos fenômenos da vida em sociedade, importante marcar que em "As regras do método sociológico", publicado pela primeira vez em 1895, Émile Durkheim (1858-1917) deixa clara a necessidade de se estabelecer a Sociologia como ciência e se propõe a defende-la como a "física" do social, engajando-se na proposta de um modelo científico que se baseia na tomada de objeto de estudo específico - no caso, o "fato social" - e a necessária reflexão sobre a postura metodológica do pesquisador, que deveria tratar tais fatos como coisas a fim de se tentar eliminar quaisquer influências subjetivas e valorativas do pesquisador na construção do saber. Nota-se a influência do Positivismo comtiano ao tentar aproximar a Sociologia do método experimental das ciências naturais.

Propondo uma abordagem funcionalista que se estabeleceu muito fortemente nas Ciências Sociais de contexto norte-americano, Durkheim esclarece que o termo fato social normalmente é empregado para designar todos os fenômenos que ocorrem na sociedade e, partindo dessa acepção, não há acontecimentos humanos que não sejam sociais. Os fatos sociais apresentam características consistem em maneiras de agir, pensar e sentir exteriores ao indivíduo e dotados de um poder coercitivo em virtude do qual se lhe impõem. Não podem ser confundidos com os fenômenos orgânicos (por consistirem em representações e ações) nem com os psíquicos (por só existirem na consciência do indivíduo), sendo constituídos por crenças, tendências e práticas do grupo tomadas coletivamente (DURKHEIM, 2007). Fica aqui explícita a ideia de que a sociedade é um todo, um campo organizado que está além das influências dos sujeitos sociais, cabendo-lhes se estabelecerem em meio a práticas e ideias que no social se dispõem. A perspectiva de que os fatos sociais existem por si, independentes de ações dos indivíduos, foi inclusive a orientação epistemológica e metodológica sugerida por Durkheim para as práticas de pesquisa em Ciências Sociais, de maneira a ser necessário estudar os fatos sociais enquanto coisas exteriores ao pesquisador, a fim de que se eliminem as influências subjetivas e valorativas na produção do saber.

Para Durkheim, não se pode explicar os fatos sociais a partir dos indivíduos pois, se a vida social fosse um prolongamento do ser individual, não a veríamos exercendo coerção sobre os indivíduos. É na natureza da vida social que se deve procurar a explicação da vida social. A sociedade não é uma simples soma de indivíduos, pois o sistema formado pelas suas associações representa uma realidade específica que tem suas características próprias. $\mathrm{O}$ autor também ressalta que os acontecimentos atuais da vida social não derivam dos acontecimentos anteriores, dosendo a relação entre eles exclusivamente cronológica. A a-historicidade surge como pressuposto para se marcar a constância e regularidade como sintomas da objetividade dos fenômenos da vida em sociedade, tornando categorias como mudança e transformação problematizações cujas causas são ligadas a rearranjos de ordem "natural" na vida em sociedade. Temáticas como jogos de poder, dinâmica simbólica e seus efeitos junto aos sujeitos sociais não eram centrais nas discussões do autor, o que atesta o caráter parcial suas colocações sobre a organização social. 
A intenção de isentar a ciência sociológica de valores e ideologias gerou intensos e calorosos debates, a começar pelo fato de os argumentos do autor trazerem, de forma os valores do próprio autor em relação ao que deve ou não ser tratado como ciência. Durkheim se mostra incoerente pela própria defesa de um valor de ciência, o que leva a inferir que a neutralidade e a plena objetividade seriam, por si, impossíveis. Outro ponto controverso é perceber a tentativa do autor de desvincular por completo a Sociologia e seu método de áreas tais como Filosofia, Psicologia e demais ciências humanas. Se todas as Ciências Humanas partilham de um mesmo objeto material de estudo - o ser humano em suas múltiplas manifestações - e diferem enquanto disciplinas independentes pelo caráter formal que buscam no estudo desse mesmo objeto material, é imprescindível considerar a interdisciplinaridade como base para o desenvolvimento de teorias que abarquem a complexidade própria do homem em meio às suas relações sociais.

Considerando Burrel e Morgan (2005) sobre os paradigmas sociológicos nos Estudos Organizacionais, a abordagem funcionalista durkheimiana tem foco na manutenção ou regulação do sistema social, com análises que se voltam ao contexto social geral e à objetividade, sem que considerar a dimensão do sujeito e de sua subjetividade, razão pela qual ele não será usado. Os demais quadrantes epistemológicos propostos pelos referidos autores (o Interpretativismo, o Estruturalismo e o Humanisno Radical) podem servir de referência mais adequada à complexidade das discussões nos Estudos Organizacionais, muito embora não seja o modelo de Burrel e Morgan que norteie as colocações propostas neste trabalho, dadas suas limitações. Os autores enfatizam limites entre abordagens, sem que sejam possíveis intersecções, reforçando a incomensurabilidade paradigmática de Thomas Kuhn (2011). Parte-se aqui do princípio, tal como propõe Paula (2012), de que a incomensurabilidade paradigmática esteja superada em razão da necessidade de se criarem saberes segundo interesses que decorrem da construção do conhecimento na realidade em determinado momento da história, orientando o pesquisador à complexificação que emerge da interpenetração das matrizes epistemológicas, como retomaremos adiante.
Karl Marx segue um caminho distinto de Saint-Simon, Comte e Durkheim, que fundam a perspectiva funcionalista e positivista nas Ciências Sociais, e se estabelece como um promotor de mudanças práticas e concretas a partir do conhecimento, declarando uma perspectiva política e nada imparcial quanto à construção do saber. Marx desenvolve sua teoria como uma crítica ao modo de produção na sociedade capitalista, com foco na mobilização dos coletivos a partir da articulação entre teoria e prática, colocando-se contrário a quaisquer dicotomias ou cisões entre realidade e ideias, uma vez que se integram numa síntese complexa. Partindo de filósofos alemães tais como Feuerbach (1804-1872) e Hegel (1770-1831), Marx ruma ao encontro da complexidade numa perspectiva dialógica e dialética, motivo, talvez, pelo qual se presentifica ainda tão fortemente nas diversas Ciências Humanas.

Em sua obra, é nítida a relevância de aspectos tais como a história e materialidade advindas das ações e práticas humanas, além de tempo e espaço como variáveis elementares na construção do conhecimento sobre o homem e o processo de construção de sua existência. Afastando-se de uma perspectiva determinista biológica, Marx toma o trabalho humano como elemento fundante da humanidade, dada sua centralidade na ontologia do sujeito social que se constitui na medida em que atua sobre a natureza. Além disso, concomitante, ao imprimir no contexto mudanças, imprime em si mesmo transformações (MARX, 2010), devido à existência de significados e sentidos que se atrelam historicamente à prática de trabalho.

Marx não escreveu um livro dedicado especificamente à metodologia das ciências sociais, mas deixou disperso em suas obras um conjunto de reflexões metodológicas, nas quais desenvolve o seu próprio método por meio da crítica ao idealismo especulativo hegeliano e à economia política clássica. A perspectiva dialética do autor aponta que a contradição e o conflito são a substancialidade que formam a realidade. Mas à dialética deve-se associar também a perspectiva da mudança, de consideração dos indivíduos em suas condições materiais de existência.

A forma como os indivíduos manifestam sua vida reflete muito exatamente aquilo que são. $O$ que coincide, portanto, com sua produção, isto é, tanto com aquilo que produzem como com a 
forma como produzem. Aquilo que os indivíduos são depende, portanto, das condições materiais de sua produção (MARX; ENGELS, 2001, p. 11).

Segundo Marx, Hegel e seus seguidores criaram uma dialética mistificada, que buscava explicar especulativamente a história mundial como autodesenvolvimento da ideia absoluta. Já os economistas clássicos naturalizavam e desistoricizavam o modo de produção capitalista, concebendo a dominação de classe burguesa como uma ordem natural das relações econômicas, a partir de um conceito abstrato de indivíduo na ideia do homo economicus. Em oposição aos filósofos idealistas e aos economistas clássicos, Marx propunha a investigação do desenvolvimento histórico das formas de produção e reprodução social, partindo do concreto para o abstrato e do abstrato para o concreto. Aponta que, na produção de análises sociais e econômicas, há erros que se justificam pela tomada de categorias de análise em seu sentido aparente, isto é, a partir de como tais categorias se apresentam à experiência sensível, mas que escondem, em essência, características contrárias a seu aspecto aparente.

Para Marx (1999), quanto mais fundo se volta na história, mais se percebe que o homem que produz é também dependente, membro de um todo maior, que é da vida em sociedade. Num primeiro momento e de forma natural, na família e na família ampliada em tribo; mais tarde, nas diversas formas de comunidade resultantes do conflito e da fusão das tribos. Somente com a sociedade burguesa, as diversas formas de conexão social confrontam o homem como meio de produzir-se a si mesmo para fins privados, como necessidade exterior àquele que produz. Daí que, para Marx, analisar os modos de produção implica analisar um determinado estágio de desenvolvimento social - da produção de indivíduos sociais.

Em sua concepção, os modos de produção concreta da vida geram a chamada infraestrutura social, a maneira como se dispõem, como se organizam os sujeitos nas relações de produção social pelo trabalho. Dela decorre outra instância, que seria de ordem ideológica e representacional, simbólica e abstrata - a superestrutura ou supraestrutura (como preferem alguns autores). Essas instâncias da vida em sociedade não são independentes, se interpenetram e uma justifica a outra, de modo dialético, embora algumas interpretações da teoria marxiana possam tomar como ponto elementar a vida econômica e a ela atribuir causalidade, inclusive, quanto à maneira como os valores e a vida jurídica se constituem, sem que se considere que também na dimensão simbólica, superestrutural, há forças contrárias à maneira de se produzir a vida econômica, mobilizando-a à mudança. Em outras palavras: embora a vida material (aspecto econômico) seja a base concreta da existência humana, ela está permeada por todos os demais aspectos da vida social, sendo igualmente importantes e centrais - tanto quanto o campo infraestrutural - os aspectos da vida simbólica na maneira como se produzem socialmente os sujeitos:

\begin{abstract}
O resultado geral a que cheguei e que, uma vez obtido, serviume de guia aos meus estudos, pode ser formulado, resumidamente, assim: na produção social da própria existência os homens entram em determinadas relações, necessárias, independentes da sua vontade; essas relações de produção correspondem a um grau determinado de desenvolvimento das suas forças produtivas materiais. A totalidade dessas relações de produção constitui a estrutura econômica da sociedade, a base real sobre a qual se eleva uma superestrutura jurídica e política, e à qual correspondem formas sociais determinadas de consciência social. O modo de produção da vida material condiciona o processo da vida social, política e intelectual. Não é a consciência dos homens que determina o seu ser; ao contrário, é o seu ser social que determina a sua consciência (MARX, 2008, p. 47).
\end{abstract}

Marx estabelece a complexidade da vida em sociedade ao articular níveis distintos e antagônicos da percepção humana na produção da realidade social, de modo a se interinfluenciarem e, mutuamente, se transformarem. Mas para que as transformações ocorram concretamente, enfatiza a dimensão da reflexividade no âmbito da coletividade, não na individualidade, tal como propõe a noção de práxis social. As colocações acerca das classes sociais e suas lutam corroboram a relevância que Marx atribui à dimensão coletiva, da vida organizada. Critica, pois, a propriedade privada como fator que desumaniza o homem à medida que, pelo trabalho, configuram-se o estranhamento e a alienação por meio da exploração de uma classe que detém os meios de se produzir concretamente a vida (recursos tais como instrumentos, matérias-primas, tecnologias etc.) em relação a outra classe que detém força produtiva a ser empregada, cooptada pelos detentores dos meios de produção. A 
ideia de luta de classes se volta consequentemente à mudança social, pois que a não correspondência entre a força de produção e as relações sociais de produção é fator preponderante para o estabelecimento de ações revolucionárias, a depender da maneira de como se apercebem os sujeitos sociais de tais contradições, emancipando-se em relação à alienação.

Muito embora Marx tenha aberto todo um contexto de complexidade em relação à forma como se articulam concreta e historicamente os sujeitos sociais e os espaços organizacionais, para alguns pesquisadores suas contribuições se assentam mais especificamente nas críticas ao modo de produção capitalista, e não diretamente a considerações da dimensão subjetiva e intersubjetiva como elementos eliciadores da vida social. Todavia, este se trata de um ponto controverso entre os diversos estudiosos do marxismo, já que, para muitos, a subjetividade em sua dimensão ontológica está diretamente contemplada nas discussões acerca da emergência do homem nas relações de trabalho.

Com Max Weber (1864-1920) surge, para muitos estudiosos nas Ciências Sociais o foco de se compreender, junto às práticas dos sujeitos e suas intencionalidades, a forma como se articulam os espaços sociais e a maneira como se constituem, a partir de tais ações, as relações sociais. Partindo do pressuposto de que as colocações de Marx se fixam nas estruturas sociais - o que leva a alguns pensadores categorizarem os estudos de Karl Marx como de natureza estruturalista, inclusive - Weber se concentra numa perspectiva compreensiva associada ao método fenomenológico, orientando-se à apreensão dos tipos puros de ação social e como eles formam uma complexa rede de relações que dão base e forma à sociedade.

Por ser posterior às colocações de Marx e Durkheim, parece-nos curioso o quanto que seu foco na ação do sujeito como forma de se criar uma teoria da vida em sociedade retoma, tal como nas colocações de Durkheim, uma perspectiva unilateral de constituição da vida, agora não mais tomando a sociedade como algo externo ao homem, uma vez que as relações sociais se fazem em meio a conteúdos significativos (sentidos) atribuídos por quem age (emissor) tomando o outro como referência (receptor), mas colocando a dimensão da vida em sociedade como decorrente de tais ações e relações, sem que lhes seja dada a complexidade devida. Nas trocas entre sujeitos, há um universo de significados que são de ordem não partilhada, subjetiva, e que atuam igualmente na maneira como se propõem os homens à organização da vida em sociedade.

Um ponto interessante também a marcar é a relevância que Weber dá à racionalidade e às colocações sobre a burocracia como forma de organização social. Tais considerações tiveram extremo impacto, influenciando as ciências sociais em geral, com especial destaque à Administração. Nas organizações, especialmente no caso daquelas de grande porte e com expressivo grau de burocratização dos processos, por exemplo, tem-se como prerrogativa que a racionalidade é condição essencial por orientar os sujeitos a atuar segundo os princípios de impessoalidade, legalidade, publicidade, moralidade e eficiência, entre outros, o que faz da burocracia um modelo de organização justo, haja vista que a decisão deve considerar o intuito, a intencionalidade maior: os objetivos organizacionais. A racionalidade é um importante elemento da dimensão simbólica em que se inserem os sujeitos sociais, cabendo-nos refletir sobre o conceito e seus usos numa organização.

As organizações sociais resultariam de relações entre atores sociais cujas ações estariam direcionadas por finalidades específicas e partilhadas. Assim, para Weber (1994), as diferentes formas organizacionais existentes na sociedade podem ser explicadas pela predominância do uso de racionalidades específicas e podem se apresentar em quatro tipos: (a) racionalidade prática - é própria do modo de vida cotidiano, no qual as atividades do dia a dia são julgadas em relação a interesses individuais, puramente práticos e egoístas; (b) racionalidade teorética - associada aos processos cognitivos, é também conhecida como racionalidade intelectual, envolve o domínio consciente da realidade pela construção de conceitos abstratos; (c) racionalidade substantiva - direciona a ação orientada por valores emancipatórios (solidariedade, liberdade, comprometimento etc.), independente dos resultados obtidos; e (d) racionalidade formal (instrumental) - direciona a ação conforme regras, leis e regulamentos institucionalizados com base no cálculo utilitário de consequências no estabelecimento de relações estratégicas entre um meio e um fim. 
Merecem destaque também as contribuições de natureza cognitivista de Herbert Simon (1916-2001), inspiradas nas colocações weberianas, que enfatizam a dimensão do planejamento e da cooperação nas trocas intersubjetivas para a estruturação das organizações. Para ele, as organizações são:

\begin{abstract}
um complexo sistema de inter-relações existente num grupamento humano. Este sistema proporciona a cada membro do grupo parte substancial de informações, pressupostos, objetivos e atitudes que entram nas suas decisões, proporcionando-lhe, igualmente, um conjunto de expectativas estáveis e abrangentes quanto ao que os outros membros do grupo estão fazendo e de que maneira reagirão ao que ele diz e faz. Ao sistema que acaba de ser descrito os sociólogos chamam de sistema de papéis, embora muitas pessoas o chamem, na intimidade, de organização (SIMON, 1979, p. 14).
\end{abstract}

Esse caráter intencional e racional, entretanto, fica limitado às possibilidades perceptivas dos sujeitos na trama de inter-relações sociais, o que traz circunstancialidade ao processo decisório e, para além da racionalidade limitada, incompletudes e por vezes incoerências, dada a abertura a influências não explícitas ou acessíveis à própria racionalidade (como a dimensão inconsciente, por exemplo).

A questão epistemológica que aqui se apresenta acerca da racionalidade como preceito da organização dos sujeitos em sociedade está longe de se esgotar no contexto acadêmico, motivo pelo qual não será tratada neste trabalho. Mesmo porque, juntamente com aspectos tais como a indeterminação quanto a explicações de fenômenos da natureza, a pluralidade de enunciados para um mesmo objeto, a pluralidade e diferenciação das culturas etc., a problematização mencionada trouxe às Ciências Humanas e Sociais, uma crise nos princípios da razão moderna no Século XX e orientaram para a necessidade de um alargamento da compreensão do termo. A esse abalo devemos acrescentar também outros importantes fatores, que são: (a) a introdução, por Karl Marx, da noção de ideologia, que mostrou que as teorias e os sistemas filosóficos ou científicos, aparentemente rigorosos e verdadeiros, escondiam a realidade social, econômica e política, e que a razão, em lugar de ser a busca e o conhecimento da verdade, poderia ser um poderoso instrumento de dissimulação da realidade, a serviço da exploração e da dominação dos homens sobre seus semelhantes; (b) a introdução feita por
Sigmund Freud do conceito de inconsciente que, por sua vez, revelou que a razão é muito menos poderosa do que a Filosofia imaginava, pois nossa consciência é, em grande parte, dirigida e controlada por forças profundas e desconhecidas que jamais se tornarão plenamente conscientes e racionais. A razão e a loucura fazem parte de nossa estrutura mental e de nossas vidas e, muitas vezes, como no fenômeno do nazismo, a razão é louca e destrutiva (CHAUÍ, 2010).

Essa crise da razão no Século XX possibilitou que novos caminhos fossem traçados nas Ciências Sociais e Humanas na construção de sistemas explicativos da realidade que buscassem superar a dicotomia objetivismo/subjetivismo. Nas Ciências Sociais Aplicadas, como é o caso da Administração, surgiram novas abordagens de se entender o contexto organizacional, para além da abordagem funcionalista, que decorre do Positivismo de se considerar a organização em sua dimensão estrutural, objetiva e racional. Entre tais abordagens, destaca-se nos Estudos Organizacionais a dimensão interpretacionista, que vislumbra a organização como uma rede complexa de interações, trocas simbólicas que atuam na constituição das subjetividades, racionalidades, poderes etc. (VERGARA; CALDAS, 2005).

Na perspectiva interpretacionista, merece destaque o construcionismo social proposto por Berger e Luckmann (2011) na obra "A construção social da realidade", buscando romper com as dicotomias presentes em clássicos da Sociologia. Os autores se voltam, inspirados pelos trabalhos de Marx, a uma perspectiva dialética, estabelecendo que não há como se pensar a constituição da realidade subjetiva ou objetiva de modo unilateral, determinado e exclusivo. Sujeitos e sociedade se interpenetram e se formam à medida que se apropriam uns dos outros. Em termos teóricos, Berger e Luckmann (2011) mencionam cinco pontos principais a serem considerados por uma teoria social numa análise da realidade: a concretude da vida social, o contexto, a cognoscitividade dos agentes, a dualidade objetivo/subjetivo e a relação tempo e espaço. Isso quer dizer que a análise da realidade social envolve o estudo das ações humanas rotinizadas, considerando o contexto em que essa rotina ocorre, bem como a capacidade dos agentes de viver, refletir e mudar tal realidade. Considera-se, ainda, que esse processo de mudança implica a dual- 
idade objetivo/subjetivo, em que a realidade objetiva é apreendida e subjetivada, ao mesmo tempo em que é transformada também a partir da subjetividade de seus agentes, dentro de tempo e espaço necessários.

Goffman (2011), por sua vez, defende uma sociologia das ocasiões, a partir da descrição de unidades naturais da interação face a face, as quais compreendem uma série de eventos, gestos, posicionamentos ocorridos nessa interação e que permite conhecer a construção da realidade social. Para o autor, representante do chamado interacionaismo simbólico, comportamentos como a preservação da fachada (entendida como layout de um papel social), a deferência, o porte, dentre outros aspectos, ajudam a entender os modos como a realidade é construída. Para Goffman, há uma série de papeis e expectativas que orientam socialmente as condutas dos diversos agentes que buscam se posicionar de forma mais ou menos coerente com tais prescrições, sob o risco de se tornarem não acreditáveis ou mesmo pejorativamente categorizados nas relações a que se propõem.

Mas se a realidade é construída por agentes cognoscitivos, mediante um processo constante de mudanças ao longo do tempo e do espaço, instaura-se a dúvida sobre até que ponto a realidade que aos sujeitos se apresenta se forma de maneira coesa e coerente com a concretude ou se de fato se apresenta como mera abstração ou ideologia. Problematiza-se, pois, a construção do conhecimento acerca da realidade. Como encontrar o que de fato é real, mediante esse processo contínuo de construção social da realidade? A partir da obra, sugere-se que a realidade objetiva e o conhecimento a seu respeito são, então, construções simbólicas a partir das contribuições de cada sujeito e sua realidade subjetiva que se entrelaçam e formam uma rede de significações plausíveis que, por sua vez, passam a orientar os próprios sujeitos produtores de tais significações.

Para esses autores interpretativistas, o sujeito social aparece como sujeito cognoscente, dado o agenciamento (poder de agir) que lhe é característico, sem que se coloquem questionamentos sobre a maneira pela qual a percepção da realidade é por tais agentes tomada subjetivamente. A subjetividade não seria outra coisa que a própria objetividade interiorizada, de modo a ser reproduzida nas rotinas sociais por intermédio das categorizações e institucionalizações, o que parece ser contraditório com a proposição de agenciamento e reflexividade dos autores. A subjetividade se desfaz e não aparece, pois, como contradição à objetividade, já que o sujeito reflexivo perde seu poder de atribuição singular de sentidos. Mas é preciso reconhecer que a escola construcionista de Berger e Luckmann e o interacionismo simbólico de Goffman instauram uma necessária discussão acerca das práticas sociais e dos papeis dos sujeitos na construção do cotidiano e do conhecimento, trazendo aos Estudos Organizacionais maior nível de complexidade que algumas das teorias clássicas anteriores, em especial as de natureza positivista.

Também no bojo dos modelos ou paradigmas de compreensão e explicação das organizações (tendo como base a proposta de Burrel e Morgan) estão as perspectivas estruturalistas. Diferentes entre si, estas abordagens trazem à pauta a ideia de que as organizações são estruturas erguidas a partir da combinação de elementos diversos (sejam concretos ou simbólicos) nas quais se inserem o homem e suas práticas. A noção de estrutura é, então, sistêmica, percebida a partir da inter-relação de si que forma um todo que não se decompõe, por sua vez, nas partes estruturantes.

No intuito de se avançar nas discussões acerca da autonomia e heteronomia dos sujeitos sociais estão as contribuições de Anthony Giddens, com especial destaque à obra "A constituição da sociedade", cujo conteúdo se volta à dimensão dos agentes sociais e seu papel na estruturação social. Não se trata de marcar a influência do campo social sobre os sujeitos como se a eles não houvesse escapatória à coerção por ele exercida, mas de se enfatizar o poder de transformação social decorrente da maneira como os agentes se posicionam em relação aos recursos de uma dada estrutura social vigente. Disso dependerá a mudança social. Giddens (2003) afirma seu intuito de promoção de dialogicidade e a tentativa de se evitar o reducionismo e demais falhas na construção de uma teoria social:

Se as sociologias interpretativas se assentam num imperialismo do sujeito, o funcionalismo e o estruturalismo propõem um imperialismo do objeto social. Uma de minhas principais ambições na formulação da teoria da estruturação é por um fim a cada um desses esforços de estabelecimento de impérios. O domínio básico do estudo das ciências sociais, de acordo com a teoria da estruturação, não é a experiência do ator 
individual nem a existência de qualquer forma de totalidade social, mas as práticas sociais ordenadas no espaço e no tempo (GIDDENS, 2003, p. 2).

Trazendo à problematização o poder de ação dos sujeitos em meio à dinâmica social, o autor defende não a ideia de atuação em estruturas cuja fixidez seja marcada, mas apela para a ideia de estruturação enquanto processo, posto que a mudança é um dos elementos constitutivos de sua teoria e ela decorre do poder de agir humano. Assim, "ser um ser humano é ser um agente intencional, que tem razões para suas atividades e também está apto, se solicitado, a elaborar discursivamente essas razões (inclusive mentindo a respeito delas)" (GIDDENS, 2003, p. 3). A agência ou agenciamento é o elemento que marca, na concepção de Giddens, como se operacionaliza o poder na dinâmica social. Para o autor, poder é poder de agir, ao contrário de outros autores que, por contraste, entre eles Parsons e Foucault, veem o poder como, acima de tudo, uma propriedade da sociedade ou da comunidade social. Assim, poder não se expressa a partir de um caráter intrinsecamente opressivo ou conflito, mas constitui o meio por meio do qual o sujeito social obtém a liberdade e a emancipação.

O social decorre, então, do processo de estruturação, concebido como "condições governando a continuidade ou transmutação de estruturas e, portanto, a reprodução de sistemas sociais" (GIDDENS, 2003, p. 29). As constituições de agentes e estruturas não são dois conjuntos de fenômenos dados independentemente, mas representam uma dualidade. De acordo com a noção de dualidade da estrutura, as propriedades estruturais de sistemas sociais são, ao mesmo tempo, meio e fim das práticas que elas recursivamente organizam. Giddens também critica a perspectiva freudiana, já que o modelo psicanalítico trouxe, com a divisão do aparelho psíquico, uma divisão do agenciamento no agente. Para relacionar o ego freudiano à agência, é necessário seguir um desvio sugerido pelos estruturalistas, com relação à descentralização do sujeito. Para Giddens, é um equívoco supor que o "eu" é o agente. A constituição do "eu" só ocorre mediante o "discurso do Outro", mas o "eu" tem que ser relacionado ao corpo enquanto esfera de ação. A palavra "eu" é, em termos linguísticos, um cambiante: o contexto de "posicionamento" social determina quem é um "eu" em qualquer situação de conversa, por meio de uma constante monitoração reflexiva. O reconhecimento da importância essencial dessa monitoração reflexiva da conduta na continuidade cotidiana da vida pessoal não significa refutar o significado das fontes inconscientes de cognição e motivação. Mas envolve prestar alguma atenção à diferenciação que separa a ação consciente da inconsciente. Consciência assume, então, uma conotação prática, ao passo que o correspondente ao inconsciente freudiano seria a consciência discursiva. $\mathrm{O}$ autor não desconsidera, entretanto, que a cognoscibilidade esteja desvinculada de uma dimensão inconsciente, mas atribui a este termo outra significação, atrelada à memória, à dimensão cognitiva e à performance discursiva dos agentes na prática social.

Apesar das importantes colocações de Giddens quanto à complexa trama de articulação entre os sujeitos sociais e os espaços organizacionais, questiona-se, mais uma vez, a forma como se apresentam a estrutura e seus elementos gerais aos sujeitos, em especial os elementos simbólicos. Entende-se que as contribuições da teoria da estruturação social ampliam as proposições do construcionismo e do interacionismo pelo diálogo com as complexas perspectivas freudiana e foucaultiana, e até pelo fato de ser uma teorização desenvolvida em contexto social atual, mas aqui se acredita ser necessário articular as propostas a outros autores que deram maior enfoque à questão simbólica das práticas sociais.

Outras contribuições relevantes são dadas pelos vieses culturalistas de Clifford Geertz (2008) e Morgan (2006) com considerações sobre a complexidade do fenômeno cultural, uma vez que são teias de significados criados historicamente e que servem de dispositivos para as ações dos sujeitos que a interpretam, gerando possíveis desacordos, fragmentações. A organização em sentido semiótico é tomada como um mosaico ou caleidoscópio de possibilidades interpretativas, coexistindo com sistemas de valores diversificados. Talvez por isso, criam-se paradigmas referenciais (estruturas) e, em meio a eles, formas de conservadorismo ao mesmo tempo em que as múltiplas possibilidades se abrem à mudança, ao dinamismo, em um movimento contraditório.

Não se deve analisar, entretanto, a dimensão semiótica e simbólica sem se considerarem as 
questões de poder, motivo pelo qual nos apegamos mais expressivamente às colocações de Bourdieu (1930-2002) como aparato explicativo à questão simbólica. Para ele, os sistemas simbólicos exercem um poder estruturante (de conhecimento do ser sobre o mundo), na medida em que são também estruturados. E a estruturação - termo que se refere ao processo também marcado na perspectiva de Giddens - decorre da função que os sistemas simbólicos possuem de integração social para um determinado consenso, no caso, o da hegemonia, da dominação. "As relações de comunicação são, de modo inseparável, sempre, relações de poder que dependem, na forma e no conteúdo, do poder material e simbólico acumulados pelos agentes" (BOURDIEU, 2006, p. 11). O que ocorre é uma relação de luta, principalmente simbólica, em que as diferentes classes estão envolvidas para imporem uma definição do mundo social conforme seus interesses. Ao retomar em suas colocações termos como classe, luta e articulação entre materialidade e simbolismo, notamos a influência de preceitos marxianos, sendo por isso perceptível a promoção de estratégias que possam minar a dominação de grupos sociais hegemônicos sobre os demais a partir de elementos como a cultura, a educação, a arte e demais aparatos que possam fazer valer a dominação pela própria legitimação dos dominados.

Bourdieu esclarece que os sistemas simbólicos diferenciam-se segundo sua instância de produção e de recepção. E a autonomia de determinado campo se constitui na medida em que um corpo especializado de produtores de discursos se desenvolve. "O poder simbólico como poder de constituir o dado pela enunciação, de fazer ver e fazer crer (...) só se exerce se for reconhecido" (BOURDIEU, 2006, p. 14). E deste modo, o poder simbólico é uma forma transformada e legitimada de outras formas de poder. Os diferentes universos simbólicos (mito, língua, arte, ciência) são formas de classificação que deixam de ser formas universais (tal como se percebe na obra de Durkheim) para se tornarem formas sociais arbitrárias, relativas a um determinado grupo. A objetividade do sentido do mundo se define pela concordância das subjetividades estruturantes e, nesse caso, tem-se a ideia de que o senso (sentido) é similar ao consenso (partilha). Portanto o poder simbólico é o poder de construção da realidade que tende a estabelecer uma ordem gnosiológica, quer dizer, "uma concepção homogênea do tempo, do espaço, do número, da causa, que torna possível a concordância entre as inteligências" (BOURDIEU, 2006, p. 9).

As ideologias, por sua vez, servem aos interesses particulares que tendem a apresentá-los como interesses universais, comuns aos sujeitos sociais. Um universo simbólico e cultural dominante contribui para a integração real da classe dominante e para uma integração fictícia da sociedade no seu conjunto, o que gera a falsa consciência das classes dominadas. Concorre, assim, para a legitimação da ordem estabelecida por meio do estabelecimento das distinções (hierarquias) e para a legitimação dessas distinções. O que se nota é que a cultura que une (como intermediário de comunicação geral, por ser dominante) é também a cultura que separa (pois que funciona como instrumento de distinção) e que legitima tais distinções compelindo todas as demais formas simbólicas e culturais ao distanciamento e à submissão em relação à cultura dominante. Aqui a dimensão dialógica e comunicacional das práticas sociais ganha destaque. Primeiro porque as relações de comunicação são, "de modo inseparável, sempre relações de poder que dependem, na forma e no conteúdo, do poder material ou simbólico acumulado pelos agentes (ou pelas instituições) envolvidos nessas relações", permitindo o acúmulo de poder simbólico (BOURDIEU, 2006, p. 11). Segundo, porque enquanto instrumentos estruturados e estruturantes de comunicação e de conhecimento é que os sistemas simbólicos cumprem sua função política de meios de imposição ou de legitimação da dominação de uma classe sobre outra.

O poder simbólico, portanto, não reside nos sistemas simbólicos, mas define numa relação. Para o autor, é interessante entender que o processo de construção social depende de como os agentes não somente incorporam e introjetam a estrutura em que estão dispostos, como também, por intermédio de seus esquemas de pensamento e ação (habitus), produzem, reproduzem e legitimam, concomitantemente, uma determinada esfera (ou campo, nos termos do autor) social. Bourdieu dialogo, assim, com o Estruturalismo e o Cognitivismo, como forma de romper com os reducionismos e o binarismo que criticamos neste trabalho, motivo pelo qual não se 
poderia deixar de abarcar suas contribuições quanto à vida organizada em sociedade.

É nítido que outras contribuições às análises organizacionais são também expressivas nas Ciências Sociais Aplicadas. Não obstante, abarcar todos os autores no âmbito das ciências sociais para fundamentar uma concepção ampla e generalista de vida organizada seria uma tarefa impossível. Escapa ao escopo deste trabalho também fazer uma apreensão de toda a história do pensamento organizacional. O que se intenta aqui é apresentar importantes perspectivas que, pela maior complexidade atribuída à articulação entre sujeitos sociais e espaços organizacionais, possam nos servir de base e parâmetro para apresentar ao leitor uma visão ampliada de organização.

\section{CONCLUSÃO: UMA NOÇÃO COMPLEXA DE ORGANIZAÇÃO}

Apesar de acreditarmos aqui que a incomensurabilidade paradigmática de Burrel e Morgan (2005) seja um fator já superado, é preciso cuidado na articulação entre as diversas perspectivas, uma vez que se voltam a conceitos e enfoques distintos, estruturando-se enquanto diferentes concepções de mundo na orientação do saber e da produção de análises e pesquisa em geral. Mas, tal como propõe Paula (2012), entende-se que a abertura à reconciliação crítica implica reconhecer o movimento de interdependência e complementaridade entre matrizes epistemológicas que possam criar pontos de intersecção entre as esferas empírico-analítica e hermenêutica, entre a hermenêutica e a crítica, entre a crítica e a empírico-analítica e entre as três esferas.

Procurou-se, assim, alocar as discussões apresentadas neste trabalho no ponto de intersecção entre os interesses práticos e emancipatórios, de maneira a ser possível fazer dialogar conceitos e perspectivas de lógica interpretativa com os de lógica dialética, haja vista o foco na articulação entre dimensão subjetiva e objetiva e a necessidade de superar as dicotomias tão presentes nas discussões acadêmicas. Assim, em relação ao entendimento de organização social, defende-se a ideia de que elas se constituem em meio às trocas intersubjetivas, de maneira complexa e multi- causal, dialógica e dialética, e se erguem em distintos níveis de realidade, sendo possíveis os rearranjos constantes entre sujeitos e, por isso, a contínua fluidez e dinamicidade dos espaços organizacionais em seus aspectos formais e informais, visíveis ou explícitos, e latentes ou tácitos.

É central o sujeito social nos processos organizacionais, como elemento dialético de formação e transformação de si e de seu contexto (em nível micro de análise). É à medida que se propõe ao outro, ao vínculo, que se materializa tanto o social (com a formação dos grupos) quanto seu Eu, pela delimitação que é dada por esse outro à referenciação de si (do sujeito), de seu estar no mundo. As possibilidades de se (re)fazer em meios aos vínculos e às possibilidades de rearranjarem os vínculos ocasionando, assim, múltiplos contextos organizacionais são tão vastas, dinâmicas e contínuas quanto a própria existência do sujeito social, o que traz fluidez às organizações, apesar de que, exatamente por se constituírem entre a dimensão material concreta e a simbólica abstrata, elas se estabelecem de modo mais ou menos estável, mediante estruturas centralizadas e/ou descentralizadas, como referenciação aos sujeitos sociais.

Os seus elementos concretos e visíveis geram formas ou dispositivos (dimensão organizacional) que viabilizam o estabelecimento de formas simbólicas prescritivas e normativas das ações dos sujeitos (dimensão institucional), fazendo coexistir, concomitantemente, o aspecto estrutural e o superestrutural, que se modificam de modo interdependente quando novos elementos passam a configurar em quaisquer dimensões.

A dimensão institucional é o nível de realidade mais abstrato que emerge das inter-relações, como uma complexa trama de valores, normas e prescrições que são tomadas pelos sujeitos como elementos referenciais em seu processo de constituição subjetiva, ao mesmo tempo em que se abre às ações dos sujeitos nas trocas cotidianas, possibilitando-lhes novas institucionalidades. Envolve racionalidades (sejam instrumentais e econômicas, sejam substantivas e valorativas), objetivos específicos - muitas vezes conflitantes entre si - que justificam a coletividade.

É preciso deixar claro, entretanto, que a dimensão institucional, apesar de simbólica e abstrata, pode exercer imenso poder de silenciamento ou des- 
personificação dos sujeitos sociais quando arraigada em elementos externos ao grupo que materializa a organização, motivo pelo qual é importante que se considerem também as relações que se estabelecem entre organizações (nível intermediário de análise) e entre instituições da vida em sociedade (nível macro de análise). Em outras palavras: pela concepção de organização que aqui se apresenta, não se deve ter em mente que haja uma dialética em absoluto quanto ao movimento de mútua formação e transformação dos sujeitos e organizações. A complexa rede social que emerge das trocas intersubjetivas está marcada por relações de poder que podem minar o próprio poder de agir dos sujeitos, quando não lhes é pertinente o movimento de análise crítica de si e de seu mundo.

Baremblitt (2002) pontua, por exemplo, com base nas contribuições do chamado Movimento institucionalista que se desenvolveu principalmente no contexto francês ao final da década de 1960, que as instituições sociais têm promovido a perda do poder de reflexão dos sujeitos sociais ao engessá-los em modelos pré-estabelecidos de organização e orientação do mundo, de maneira que a autoanálise da coletividade em relação a si, seus interesses, seus conflitos e demandas é uma possível saída contra a rigidez das formas de dominação social, por meio do chamado movimento instituinte dos grupos e coletividades. Amparando-se em contribuições advindas da Psicanálise, do marxismo e de abordagens pós-estruturalistas, o Movimento Institucionalista visa deflagar nos coletivos processos de "olhar para si", por meio da autoanálise e da autogestão, o que consistiria em irromper nos grupos e organizações o protagonismo frente aos seus problemas, necessidades, interesses, desejos e demandas, a fim de que possam enunciar, compreender e (re)adquirir um "pensamento e um vocabulário próprio que lhes permita saber acerca de sua vida" (BAREMBLITT, 2002, p. 17), muitas vezes por conta da ação de experts ou agentes externalizantes que atuam em prol de saberes dominantes que causam a alienação. Assim, é imprescindível no âmbito organizacional a constante vigília dos limites e capacitações dos sujeitos em meio à complexa e emaranhada trama que se constitui a partir das múltiplas trocas intersubjetivas, por conta das ações e relações de poder e dominação, além das armadilhas que possam decorrer da articulação de elementos de natureza consciente ou inconsciente.

Naturalizar a concepção de organizações como estruturas fixas e dadas a priori em relação à constituição subjetiva seria minguar as possibilidades de mudança social, posto que desconsiderar-se-ia o poder de ação dos sujeitos que se engendram no processo de instituição do social. Nos Estudos Organizacionais, espera-se que as práticas de pesquisa e intervenção possam considerar a complexidade própria da articulação entre sujeitos X organizações, orientando-lhes, a partir da reflexividade e do criticismo, à construção de discursos, saberes e demais formas simbólicas que efetivem as mudanças necessárias para a qualidade de vida e a possível equidade de possibilidades juntos aos sujeitos inseridos em tais espaços, considerando sua diversidade de interesses.

\section{REFERÊNCIAS}

BAREMBLITT, G. Compêndio de análise institucional e outras correntes. 5. ed. Belo Horizonte: Instituto Felix Guattari, 2002.

BASTOS, A. V. B.; LOIOLA, E.; QUEIROZ, N. ; SILVA. T. D. Conceito e perspectivas de estudos das organizações. In: ZANELLI, J. C.; BORGES-ANDRADE, J. E.; BASTOS, A. V. B. (Org.). Psicologia, Organizações e Trabalho no Brasil. Porto Alegre: Armed, 2004. p. 63-90.

BERGER, P. L.; LUCKMANN, T. A construção social da realidade. 33. ed. Petrópolis: Vozes, 2011.

BOURDIEU, P. O Poder simbólico. 14. ed. Rio de Janeiro: Bertrand Brasil, 2006.

BURREL, G.; MORGAN, G. Sociological paradigms and organisational analysis: elements of the sociology of corporate life. Burlington: Ashgate, 2005.

CHAUÍ, M. Convite à filosofia. 14. ed. São Paulo: Ática, 2010.

DURKHEIM, É. As regras do método sociológico. 3. ed. São Paulo: Martins Fontes, 2007. 
GEERTZ, C. A interpretação das culturas. Rio de Janeiro: LTC, 2008.

GIDDENS, A. A constituição da sociedade. São Paulo: Martins Fontes, 2003.

GOFFMAN, E. Ritual de interação. Petrópolis: Vozes, 2011.

KUHN, T. S. A estrutura das revoluções científicas. 11. ed. São Paulo: Perspectiva, 2011.

MARX, K. O capital: crítica da economia política. Livro I. Vol. I. 27. ed. Rio de Janeiro: Civilização Brasileira, 2010.

MARX, K. Contribuição para a crítica da economia política. 2. ed. São Paulo: Expressão Popular, 2008.

MARX, K. O método da Economia Política. In: MARX, K. Para a crítica da economia política. São Paulo: Nova Cultural, 1999. p. 39-46.

MARX, K.; ENGELS, F. A ideologia alemã. 2. ed. São Paulo: Martins Fontes, 2001.

MORGAN, G. Imagens da organização. 2. ed. São Paulo: Atlas, 2006.

PAULA, A. P. P. Repensando os estudos organizacionais: o círculo das matrizes epistemológicas e a bordagem freudo-frankfurtiana. 2012.233 f. Tese (Professor Titular) - Faculdade de Ciências Econômicas, Universidade Federal de Minas Gerais, 2012.

SIMON, H. A. Comportamento administrativo. 3. ed. Rio de Janeiro: FGV, 1979.

VERGARA, S. C.; CALDAS, M. P. Paradigma interpretacionista: a busca da superação do objetivismo funcionalista nos anos 1980 e 1990. Revista de Administração de Empresas, São Paulo, v. 45, n. 4, p. 66-72, out./dez. 2005.

WEBER, M. Economia e sociedade. V. 1. Brasília: UnB, 1994. 